\title{
Prevalence and Risk Factors of Cervical Dysplasia among Human Immunodeficiency Virus Sero-Positive Females on Highly Active Antiretroviral Therapy in Enugu, Southeastern, Nigeria
}

\author{
Cornelius Osinachi Ogu ${ }^{1 *}$, Peter Uwadiegwu Achukwu ${ }^{1}$, Peter Onubiwe Nkwo ${ }^{2}$
}

\begin{abstract}
Objective: Evaluation of prevalence and risk factors of cervical dysplasia among Human Immunodeficiency Virus sero-positive (HIV+ve) females on Highly Active Antiretroviral Therapy (HAART) attending HIV clinic at University of Nigeria Teaching Hospital (UNTH) Enugu, Southeastern, Nigeria. Methods: Structured questionnaire was used to obtain socio-demographic and risk factors data. Cervical specimens were collected from $105 \mathrm{HIV}+\mathrm{ve}$ females on HAART and 104 HIV seronegative (HIV-ve) females. Pap smears were collected using cytobrush and Ayre's spatula in a secluded place. Smears were made on slides and placed in 95\% ethyl alcohol for conventional Pap staining and the cytobrush washed into the preservative containers for later Immunocytochemistry staining. Blood samples were used for HIV screening. Immunocytochemistry activity using anti-P16INK4A was carried out on the Pap smears that were positive for cervical dysplasia. Results: Pap staining showed prevalence of cervical dysplasia among HIV+ve on HAART 19.05\%, (ASCUS 14.29\%, LSIL 3.81\%, HSIL 0.95\%) whereas HIV-ve was $6.73 \%$, p = 0.008. Only the HSIL $0.95 \%$ was positive for P16INK4A. Odds ratios at 95\% Confident Interval of the risk factors of cervical dysplasia were thus; HIV+ve, 3.26 (1.31-8.09), education less than secondary school 3.23 (1.25-8.37), polygamy 3.23 (1.25-8.37), smoking $1.36(0.15-12.10)$, married $2.08(0.43-2.31)$, grand multi gravidity $1.72(0.72-4.11)$, grand multi parity $1.54(0.66-3.61)$, positive history of sexually transmitted diseases 2.49 (1.06-5.80). Uptake of cervical cancer screening was low in both study groups, 7 (6.7\%) among HIV+ve on HAART and 14 (13.5\%) among HIV-ve females, P = 0.102. Conclusion: HAART had cytoprotective effect against cervical dysplasia in HIV+ve females, by reducing progression of ASCUS to LSIL, HSIL and cervical cancer. Progression from normal to ASCUS increased which could be due to latency or/and prolonged persistent high risk HPV and HIV infections, of the most sexually active age group before diagnosed of HIV.
\end{abstract}

Keywords: Cervical dysplasia- HIV sero-positive- Highly Active Antiretroviral Therapy- Risk factors

Asian Pac J Cancer Prev, 20 (10), 2987-2994

\section{Introduction}

Cervical cancer can be avoided if detected early enough and treated. Pre-cancerous lesions are detectable for ten years or greater, before cancer develops (Mutyaba et al., 2006). Cervical cancer is the commonest genital cancer worldwide and one of the leading causes of death from cancer among women in developing countries (World Health Organisation 2012). Rates are highest in Central America, Sub Saharan Africa and Melanesia (WHO 2012). In Nigeria, cervical cancer accounts for $59-77 \%$ of gyneacological cancer, (Gharoro 1999; Galadanci et al., 2003; Aboyeji et al., 2004; Kyari et al., 2004; Mohammed et al., 2005; Mutihir 2005).

UNAIDS, (2014), reported that Nigeria carries the second highest HIV/AIDS burden in the world, with 3.4 million people living with HIV by the end of 2014 . The National Prevalence as at 2014 was $4.1 \%$. HIV infection and cervical cancer disease are common in the most populous black nation in the world - Nigeria (WHO/ ICO 2010). Enugu state has the highest prevalence of HIV infection in the southeastern region (FMOH 2006).

Cervical cancer became Acquired Immunodficiency Syndrome (AIDS) defining illness among women with HIV in 1993 (CDC, 1993). HIV+ve females have increased prevalence compared to general population with standardized incidence ratios (SIRs) of 4.2 to 8.9 (Chaturvedi et al., 2009). Prevalence of cervical dysplasia among HIV+ve women in Nigeria differ in different regions, 11-56\%, (Chama et al., 2005; Arnolu et al., 2011;

${ }^{1}$ Department of Medical Laboratory Sciences, Faculty of Health Sciences and Technology, ${ }^{2}$ Department of Obstetrics and Gynaecology, Faculty of Medical Sciences, College of Medicine, University of Nigeria Nsukka, Nigeria. *For Correspondence: cornelius.ogu@unn.edu.ng 
Dim et al., 2011; Lawal et al., 2017; Muhammad et al., 2017). Hence, by 2003, WHO recommended HAART for HIV+ve irrespective of the CD4+ cell count (WHO, 2004). Kaposi's sarcoma and Non Hodgkin Lymphoma declined after introduction of HAART but cervical cancer reduction was marginal (Ghebre, 2017). The burden of HIV and cervical cancer diseases are concentrated in Sub Saharan Africa. Cervical cancer runs a more fulminant course in HIV+ve women (CDC, 1993).

However, the most important risk factor of cervical cancer is chronic persistent oncogenic Human Papillomavirus (HPV) infection. Women with HIV are more likely to have persistent HPV, common in low and middle income countries (LMIC) (Torre et al., 2015). Speculation that HIV infection and consequent immunodeficiency resulting from infection negatively affects HPV clearance (Hankins et al., 2000), consequently increases prevalence and incidence of cervical dysplasia and cervical cancer.

It was expected that introduction of HAART, which decreases viral load and improves $\mathrm{CD}+4$ cell, would enhance clearance of HPV thereby reducing incidence and prevalence of cervical dysplasia. Paucity of report about cytoprotective effect of cervix by HAART exists in our region and Nigeria, hence this research studied the cytoprotective effects of HAART on the cervix of HIV+ve females in Enugu, Nigeria.

The aim of this study was therefore, to evaluate the prevalence and risk factors of cervical dysplasia among HIV+ve females on HAART who attend HIV clinic at UNTH, Enugu, southeastern, Nigeria.

\section{Materials and Methods}

This was a cross sectional, comparative study. This study was conducted in Enugu state, Southeastern Nigeria at UNTH. UNTH is the largest tertiary hospital in the region and serve as major reference hospital. It has the largest HIV center in the region and serves the region and beyond.

Minimum sample size (n) was calculated using Pocock (1983) and Sealed Envelope Ltd. (2012)

Percentage 'success' in control that is prevalence of abnormal cervical smear as studied in Enugu was 12.2\% (Chukwuali et al., 2003)

Percentage 'success' in experimental group that is prevalence of cervical pre-cancer and cancer in the study population of HIV-positive women in Nigeria was $6 \%$, (Ononogbu et al., 2013).

Sample size required for each group $=95$

Adjustment for non compliance or cross over $=10 \%$ of $95=9.5 \uparrow 10$

Total sample size $=210$

$$
\mathrm{n}=\frac{f(\alpha / 2 \beta) \times[P 1 \times(100-P 1)+P 2 \times(100-P 2)]}{(P 2-P 1)}
$$

Ethical approval document was obtained from the ethical committee on research, UNTH Enugu. (NHREC/05/01/2008B-FWA00002458-1RB00002323). Letters of introduction were written to HIV center and Family planning unit, Obstetrics and Gynaecology UNTH
Enugu to enable us use their facilities for the research. Written and signed informed consents were obtained from each participant with assured confidentiality of results. Participants whose results were positive for cervical lesions were referred for further investigation and management at $\mathrm{O}$ and $\mathrm{G}$ department UNTH.

Participants included females aged between $18-65$ years, married and single non virgins who consented. The research excluded pregnant women, cervical cancer patients, menstruating females, previous HPV testing and/or Pap smear of less than 6 months, past hysterectomy, treatment of pre-malignant or malignant disease and mentally unstable females.

Data were collected from July 2018 - January 2019. Data were collected using structured self and interviewer administered questionnaire. The questionnaire comprised of section-A: Socio-demographic characteristics, section-B: Risk factors of cervical dysplasia.

Sampling was non probability. The targeted were those females who attend HIV clinic at UNTH, Enugu, Gynaecology clinic, family planning clinic and staff of the hospital. Specimens were collected from participants, who consented and passed the inclusion criteria in a secluded area in the hospital. Samples were collected from 105 HIV+ve females on HAART who attend HIV clinic at UNTH and 104 HIV-ve females who served as control. Each participant had specific coded number.

Papanicolaou staining and Immunocytochemistry (ICC) staining for tumour marker P16INK4A using conversional Pap staining technique and thin preparation from liquid based cytology respectively were done. Specimens were collected from the endocervix and ectocervix using cytobrush and Ayre's spatula for Pap smear and immunocytochemistry by trained nurses, Doctors and Medical Laboratory Scientists.

Pap smears were stained using Standard Operating Procedure for convetional Papanicolaou staining technique and sent to Cytopathologists/Histopathologists for microscopy and photomicrography. Report was according to Bethesda system of classification (2001) in Solomon et al., (2002).

Immunocytochemistry was carried out using mouse monoclonal anti-P16INK4A antibody. The analyses were done on only those Pap smear that had cervical dysplasia after Pap staining. Following standard protocol and company's manual. Immunocytochemistry reagents were procured from Richard-Allan Scientific ${ }^{\circledR}$, USA. Report was according to Han et al., (2008).

Blood samples were collected for HIV screening and confirmation using ELISA rapid test kits. HIV screening was carried out following the company's instruction manuals. DETERMINE ${ }^{\circledR}$ rapid kit.

The data obtained were analyzed using Statistical package for Social Sciences 20 and Microsoft ${ }^{\circledR}$ Excel statistical package at statistical significance level of 0.05 . Chi-square $\left(\mathrm{x}^{2}\right)$ was used to compare the results of the two groups of participants, Odds ratios, $95 \%$ Confident Interval was used to determine association between risk factor and cervical dysplasia. Student t-test for comparison of means, tables for data presentation, mean and standard deviations were used for continuous variables. 


\section{Results}

A total of 209 females actively participated in this research; 105 HIV+ve females on HAART and 104 HIV-ve females as control. The mean ages of the HIV+ve and -ve females were $42 \pm 4$ years and $41.7 \pm 5.5$ years respectively, $\mathrm{P}=0.65$. HIV+ve on HAART had $43-47$ years as modal group $29.5 \%(n=31)$ whereas age group 18-27 scored $0 \%$. The modal age group for HIV-ve was 38-42 years $23.1 \%(n=24)$ and least age groups were $18-22$, 23-27 and 63-67 1.9\% $(n=2)$. There was very highly significant difference in the marital status of the two groups of study $\mathrm{p}=0.00001$; HIV + ve had more divorcees and widows than HIV-ve (8.6\% vs $1.9 \%),(25.7 \%$ vs $3.8 \%)$ respectively and $88.9 \%(n=24 / 27)$ of the HIV+ve widows testified that their husbands died of HIV infections.

Majority of the participants were from Enugu state; HIV-ve $56.7 \%(n=60)$, HIV+ve $76.2 \%(n=80)$. There was very highly significant difference in the educational status of the groups $\mathrm{p}=0.00001$; more HIV-ve $79.8 \%$ attended higher institution than HIV+ve $33.3 \%$. There was very highly significant difference in the occupational status of the two groups $\mathrm{p}=0.00001$; HIV-ve had more civil servants compare to HIV+ve (63.5\% vs $33.3 \%)$. Cervical Cancer Screening (CCS) uptake of the two groups, HIV-ve vs HIV+ve $(13.5 \%$ vs $6.7 \%), p=0.10$ though, both low. HPV vaccine receipt was low in both groups HIV+ve had $0 \%$ whereas HIV-ve had $4.8(\mathrm{n}=5), \mathrm{p}=0.095$. Details are on supplementary Table 1.

Prevalence of cervical dysplasia was $12.92 \%(n=27)$ among the participants which included $19.05 \%$ among HIV+ve females on HAART and $6.73 \%$ among HIV-ve females. There was statistically significant difference between the two groups, Odds Ratios at 95\% Confidence Interval, OR (CI 95\%) 3.26 (1.31-8.09) $\mathrm{p}=0.011$. The commonest category of cervical dysplasia was Atypical Squamous Cell of Undetermined Significance (ASCUS); $14.29 \%$ in HIV+ve on HAART and $4.81 \%$ in HIV-ve females. Also the prevalence of each category was higher among HIV+ve females on HAART as shown on Table 1. Furthermore, the Pap smear staining results showed higher inflammation among HIV+ve on HAART $25.71 \%$ and $13.46 \%$ among HIV-ve, OR (CI 95\%) 2.76 $(1.33-5.71) \mathrm{p}=0.0062$. Atypical Squamous Cell cannot exclude High-Grade Squamous Intraepithelial Lesion (ASC-H) was $0.0 \%$.

The Immunocytochemistry (ICC) analysis for tumour marker, P16INKA4 activity done on the Pap smears, positive for cervical dysplasia $12.92 \%(n=27)$ showed positive result only on the HSIL specimen $0.95 \%$ (1/105), which signified cervical cancer.

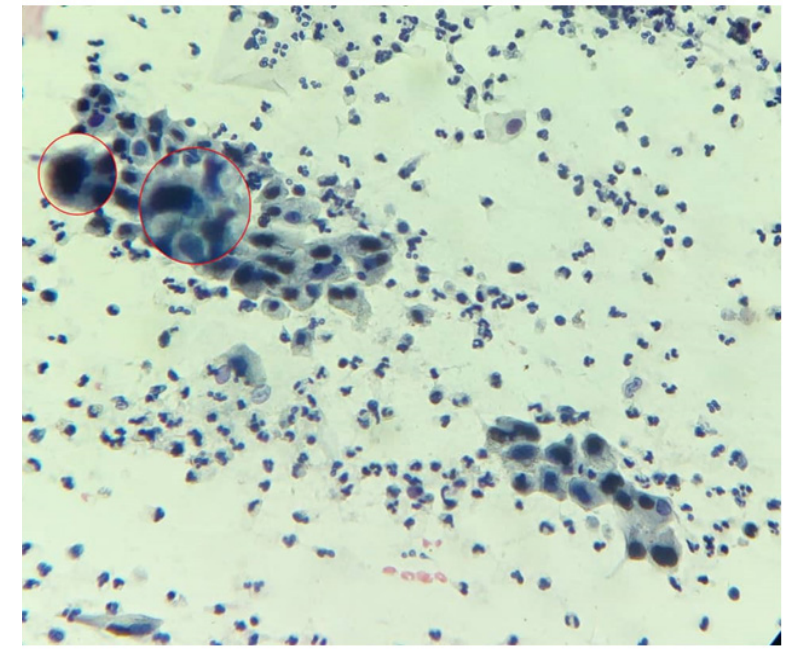

100x

Figure 1. Shows the High-Grade Squamous Intraepithelial Lesion (HGSIL).

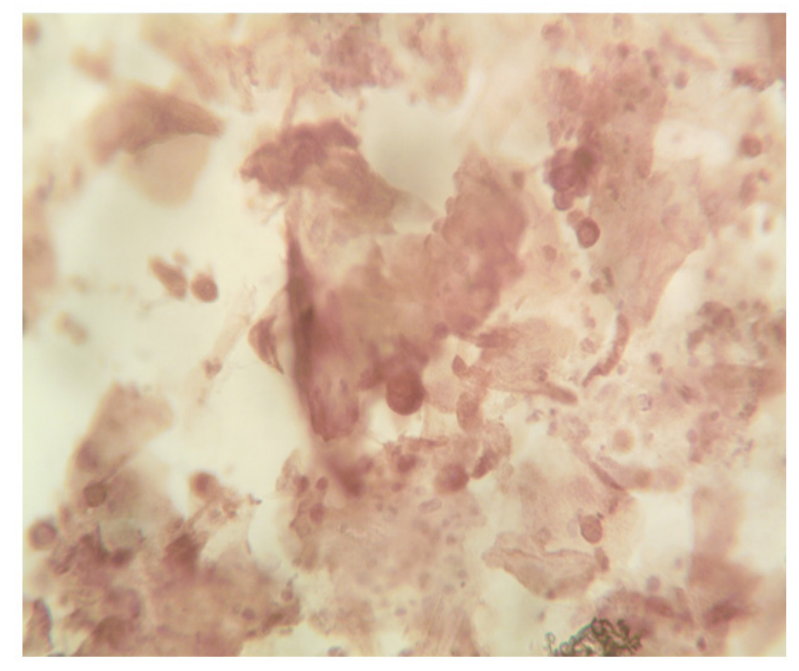

400x

Figure 2. Shows Positive Immunocytochemistry (P16INKA4) Activity on the HGSIL Specimen.

Majority of the risk factors of cervical dysplasia among the study groups showed positive association, OR (CI 95\%): HIV+ve 3.26 (1.31-8.09) p=0.011; age above 35 years 2.11 (0.60-7.38); married 2.08 (0.43- 2.31); less than secondary school $2.05(0.82-5.10)$; smoking 1.36 (0.15-12.10); gravidity above four $1.72(0.72-4.11)$; parity above four $1.54(0.66-3.61)$; polygamy $3.23(1.25-8.37)$ $\mathrm{p}=0.02$; history of STDs/GTIs $2.49(1.06-5.80) \mathrm{p}=0.04$. details are showed on Table 2.

Our result showed that $80 \%$ of HIV+ve participants commenced HAART less than 1 year after diagnosis, while

Table 1. Prevalence of Cervical Dysplasia between HIV+ve Females on HAART and HIV -ve Females

\begin{tabular}{|c|c|c|c|c|c|c|c|}
\hline & \multicolumn{3}{|c|}{ Cervical dysplasia - positive } & \multicolumn{4}{|c|}{ Cervical dysplasia -negative } \\
\hline & ASCUS (percent) & LSIL (percent) & HSIL (percent) & TOTAL (percent) & Inflammatory (percent) & Normal (percent) & TOTAL \\
\hline HIV +VE (105) & $15(14.29)$ & $4(3.81)$ & $1(0.95)$ & $20(19.05)$ & $27(25.71)$ & $58(55.23)$ & 105 \\
\hline HIV -VE (104) & $5(4.81)$ & $2(1.92)$ & 0 & $7(6.73)$ & $14(13.46)$ & $83(79.81)$ & 104 \\
\hline TOTAL (209) & $20(9.57)$ & $6(2.87)$ & $1(0.48)$ & $27(12.92)$ & $41(39.01)$ & $141(67.46)$ & 209 \\
\hline
\end{tabular}

ASCUS, Atypical Squamous Cell of Undetermined Significance; LSIL, Low-grade Squamous Intraepithelial Lesion; HSIL, High-grade Squamous Intraepithelial Lesion; HIV+ve, Human Immunodeficiency Virus sero-positive; HIV-ve, Human Immunodeficiency Virus sero-negative. 
Table 2. Relationships between Risk Factors and Cervical Dysplasia Outcome among the Studied Population

\begin{tabular}{|c|c|c|c|}
\hline \multirow[b]{2}{*}{ Variables } & \multicolumn{2}{|c|}{ Cervical Dysplasia } & \multirow[t]{2}{*}{ Odds Ratio (95\% CI) P-value } \\
\hline & $\begin{array}{c}\text { Positive } \\
{[\mathrm{n}=27 \text { (percent) }]}\end{array}$ & $\begin{array}{c}\text { Negative } \\
{[\mathrm{n}=182(\text { percent })]}\end{array}$ & \\
\hline Age (Years) & & & $2.11(0.60-7.38)$ \\
\hline$\geq 35$ & $24(88.9)$ & $144(79.1)$ & $\mathrm{P}=0.24$ \\
\hline$<35$ & $3(11.1)$ & $38(20.9)$ & \\
\hline HIV Status & & & $3.26(1.31-8.09)$ \\
\hline Seropositive on HAART & $20(74.1)$ & $85(46.7)$ & $\mathrm{P}=0.01 * *$ \\
\hline seronegative & $7(25.9)$ & $97(53.3)$ & \\
\hline Marital Status & & & $2.08(0.43-2.31)$ \\
\hline Married & $25(92.6)$ & $156(85.7)$ & $\mathrm{P}=0.34$ \\
\hline single & $2(7.4)$ & $26(14.3)$ & \\
\hline Educational Status & & & $3.23(1.25-8.37)$ \\
\hline$<$ Secondary & $8(29.6)$ & $31(17.0)$ & $\mathrm{P}=0.12$ \\
\hline$\geq$ Secondary & $19(69.4)$ & $151(83)$ & \\
\hline Marital Setting & & & $3.23(1.25-8.37)$ \\
\hline Polygamy & $8(37)$ & $22(17)$ & $\mathrm{P}=0.02 *$ \\
\hline Monogamy & $17(63)$ & $151(83)$ & \\
\hline Occupation & & & $0.69(0.31-1.56)$ \\
\hline Non civil servants & $12(44.4)$ & $98(53.8)$ & $\mathrm{P}=0.36$ \\
\hline Civil servants & $15(55.6)$ & $84(46.2)$ & \\
\hline Smoking & & & $1.36(0.15-12.10)$ \\
\hline Yes & $1(3.7)$ & $5(2.7)$ & $\mathrm{P}=0.78$ \\
\hline No & $26(96.3)$ & $177(97.3)$ & \\
\hline Gravidity & & & $1.72(0.72-4.11)$ \\
\hline$>4$ & $17(63)$ & $80(44)$ & $\mathrm{P}=0.21$ \\
\hline$\leq 4$ & $10(37.0)$ & $81(44.5)$ & \\
\hline Parity & & & $1.54(0.66-3.61)$ \\
\hline$>4$ & $11(40.8)$ & $41(22.5)$ & $\mathrm{P}=0.32$ \\
\hline$\leq 4$ & $16(59.3)$ & $92(50.5)$ & \\
\hline Life Time Sex Partners & & & $0.78(0.33-1.84)$ \\
\hline$\geq 2$ & $18(66.7)$ & $131(72.0)$ & $\mathrm{P}=0.57$ \\
\hline 1 & $9(33.3)$ & $51(28.0)$ & \\
\hline Coitarche & & & $0.90(0.23-4.87)$ \\
\hline$\leq 15$ & $3(11.1)$ & $22(12.1)$ & $\mathrm{P}=0.88$ \\
\hline$>15$ & $24(88.9)$ & $160(87.9)$ & \\
\hline Hormone Contraceptive USE & & & $0.98(0.61-1.57)$ \\
\hline Yes & & & $\mathrm{P}=0.96$ \\
\hline \multirow[t]{2}{*}{ No } & $7(25.9)$ & $48(26.4)$ & \\
\hline & $20(74.1)$ & $134(73.6)$ & \\
\hline History of STDs/GTIs & & & $2.49(1.06-5.80)$ \\
\hline Yes & $18(66.7)$ & $81(44.5)$ & $\mathrm{P}=0.04^{*}$ \\
\hline No & $9(33.3)$ & $101(55.5)$ & \\
\hline
\end{tabular}

91.4\% have taken HAART for more than 1 year. Details are shown on supplementary Table 2 .

\section{Discussion}

Our study showed significantly higher prevalence of cervical dysplasia among HIV+ve females on HAART compared to HIV-ve females, which is consistent with 2990 Asian Pacific Journal of Cancer Prevention, Vol 20 previous studies about the relationship between HIV, HPV and cervical precancerous lesion (Blitz et al., 2013; Ezechi et al., 2014). From our study, the prevalence of cervical dysplasia among HIV+v on HAART and HIV-ve females were higher than report of Dim et al., (2011) who worked at the same centre but on HIV+ve women not on therapy; (HIV+ve; SIL 12.6\%, ASCUS 1.3\%, LGSIL $8.3 \%$, HGSIL $3.3 \%$, inflammation $14.0 \%$, for HIV-ve; 
SIL 4.6\%, ASCUS 4.4\%, LGSIL 3.3\%, HGSIL 1.3\% inflammation 10.7). Some reports from other centers were also lower than ours (Anorlu et al., 2003, Durowade et al., 2012; Pimentel et al., 2013; Ezechi et al., 2014), but our report was lower than recent report of Kim et al., (2013); Lawal et al., (2017) in Abuja , Nigeria; Ugbuaja et al., (2017), which also worked on HIV+ve women not on therapy. The increase in ASCUS which was the contributor to higher prevalence in our study, could be due to risky sexual behavior among HIV+ve females on HAART as reported in previous studies that inception of HAART prompted HIV+ve to indulge in risky sexual behaviors (Chow et al., 2012; Ganesan et al., 2012). It could also be attributed to delay of the most sexually active group of females to avail themselves for voluntary counseling, testing and treatment, which prolongs the persistent infection of the cervix by oncogenic HPV and HIV infection. It could also be due to period of latency before cervical dysplasia manifested. Low perception of risk factors and lack of awareness about cervical cancer screening amongst women and challenges of availability to cervical cancer screening for early detection of disease have been reported amongst factors causing increasing incidence and mortality from cervical cancer in developing countries, (Ayinde et al., 2004, Dim et al., 2009; Ezechi et al., 2013).

However, from our study ASCUS was the actual contributor of higher prevalence of cervical dysplasia in our report compared to that of Dim et al., 2011 and supported by prior study of Blitz et al., (2013) which reported that rate of progression from normal to; ASCUS, LSIL HSIL and ICC were higher compared to rate of regression from these categories to normal in HIV +ve on HAART. They attributed this to presence of high risk HPV types and increased number of sexual partners, though generally progression and incidence of cervical dysplasia was reduced by HAART. Kim et al., (2013) during their study, at a stage termed "progression visit" noticed that $35 \%$ had progressed to ASCUS, $0.37 \%$ to ASC-H, $57 \%$ to LGSIL, $7 \%$ to HGSIL and $0.41 \%$ to cancer. From our study, other categories, LSIL and HSIL were of lower prevalence compared to Dim et al., (2011) and reports from outside our study center on HIV+ve not on therapy, hence one can say that HAART reduces progression of cervical dysplasia among HIV+ve females, which is consistent with some previous reports (Minkoff et al., 2010; Alder et al., 2012; Firnhaber et al., 2012; Kim et al., 2013; Blitz et al., 2013; Ezechi et al., 2014; Katz et al., 2016). Firnhaber et al., (2012) concluded that HAART use reduced the rate of incidence and progression of cervical lesions among HIV+ve females and was dependent on duration of regimen but Menon et al., (2017), reported in their systematic review of effects of HAART on cervical dysplasia in sub Saharan Africa, suggested that CD4+ cell count may have a more instrumental role in cervical oncogenesis or the integration of the latent reservoir throughout the body than either HAART use or the treatment duration on the prevalence of CIN 2 and CIN 3. Minkoff et al., (2010) concluded that effective and adherent HAART use was associated with a significantly reduced burden of HPV infection and Squamous
Intraepithelial Lesions (SILs).

The ICC analysis for tumour marker, P16INKA4 activity showed positive result only on the HSIL specimen, which signified cervical cancer prevalence of $0.95 \%$, which is similar as reported by Kim et al., (2012). ICC is the most sensitive technique to detect cancerous lesion, hence use of ICC will help to remove over diagnosis or under diagnosis of cervical cancer. ICC can be used to evaluate all cases of cervical dysplasia which can increase accuracy of diagnosis and management of cervical dysplasia.

From our study, the age distribution signified that early youthful ages were not captured, probably because they shy away from the tests or do not actually avail themselves for voluntary counseling, testing and treatment or don't come for HAART. Studies on these younger ages are worth carried out because these are the most sexually active ages and are at higher risk of HIV infections (WHO, 2010) and Human papillomavirus infections. Human Papilomavirus is regarded as the primary etiologic agent of cervical cancer and transmission is basically by sexual intercourse, (Anorlu, 2008; Oakeshot et al., 2012). Absence or reduced number of these ages in this study could signify that most HIV positive female are exposed to high risk Human Papillomavirus and other risk factors of cervical dysplasia long time before screening, hence this could be one of the reasons HPV clearance is delayed among HIV positive female on HAART leading to failure in significant decrease or regression of cervical dysplasia among HIV positive females on HAART. Result of our research showed that more of the HIV+ve had first sexual intercourse between 10-19 years compared to HIV-ve females. We suggest that HPV vaccine, where and when available should be introduced as early as from 13 years and once a woman debut on sexual intercourse, to enhance protection against $\mathrm{HPV}$ and subsequent cervical dysplasia.

Educational level showed that HIV-ve attended higher levels of education compared to the HIV+ve females. Our report was consistent with previous reports of Lawal et al., (2017) and Dim et al., (2011). Higher educational level among females can help to reduce HIV infection and cervical dysplasia. Lower educational status will leave them with low income jobs which can expose them to HIV infection and cervical dysplasia. Most of the HIV-ve engaged with civil service jobs as against HIV+ve females, who were engaged in trading, farming, self employment and house wives. HIV+ve females engaged in jobs that highly expose them to HIV infections due low income earning, Lawal et al., (2017) also had similar report from their research.

During our study, only $30 \%$ of HIV+ve offered free screening, accepted testing unlike in prior study by Odafe et al., (2013), who reported that $96.5 \%$ acceptance rate, similar with findings from studies in Kenya and Mozambique that reported acceptance rates of $87 \%$ and $86 \%$, respectively, of cervical cancer screening using VIA technique, (Huchko et al., 2011; Audet et al., 2012). Nonetheless screening for cervical cancer in Nigeria remains poor, (Dim et al., 2009), this was also found in our research were uptake of cervical cancer screening and HPV vaccine among the participants were 
very low. This could be attributed to low perception and lack of awareness of the advantages of Cervical Cancer Screening (CCS) or because we don't have organized CCS programme in Nigeria. Women who fail to go for CCS are at higher risk of cervical cancer.

Results of risk factors of cervical dysplasia between the studied groups showed statistically significant difference between the two groups in number of life sex partners, age at first sexual intercourse, and STDs/GTIs, $\mathrm{p}<0.05$. From our research, associations showed that risk factors of cervical dysplasia included ages equal to or above 35 years, HIV+ve even on HAART, married women, educational status of less than secondary school, polygamous marriage, smoking, gravidity above 4 , grand multi parity, positive history of STDs/GTIs. These were consistent with previous reports (Partridge et al., 2007; Oakeshott et al., 2012). Life sexual partner of more than two is not associated with cervical cancer unlike reported in previous works above.

In conclusion, HAART had cytoprotective effects against progression of ASCUS to LSIL, LSIL to HSIL and to Invasive Cervical Cancer but failed to prove so from normal cervix to ASCUS in HIV+ve females in Enugu, Nigeria. Failure of the most sexually active females to be captured in this research could be one of the reasons for the increased progression from normal to ASCUS and reduced regression of cervical dysplasia. Immunocytochemistry can be of great advantage in the accurate diagnosis of cervical cancer. Cervical Cancer Screening should be introduced as routine investigation for HIV+ve females in Enugu, Nigeria. Effective cervical cancer screening and HPV vaccination programme will be of great advantage in our region.

\section{Acknowledgements}

We wish to acknowledge the participants. We also acknowledge the Pathologists, Medical Laboratory scientist, Nurses and staff of University of Nigeria Teaching Hospital (UNTH) Ituku/Ozalla Enugu who assisted us at various levels. Our appreciation goes to administration and staff of HIV center and Obstetrics and Gynaecology Department UNTH Enugu, School of Post Graduate Studies, Department of Medical Laboratory Sciences and Faculty of Health Sciences and technology, University of Nigeria Nsukka.

\section{Funding}

This research was fully funded by the participants.

\section{Approval}

The research was part of an approved thesis by School of Post Graduate Studies and Department of Medical Laboratory Sciences University of Nigeria Nsukka.

Research was not approved by any Scientific body.

\section{Conflict of interest}

There was no conflict of interest.

\section{Ethical Approval}

Ethical approval document was obtained from the Ethical Committee on Research, UNTH Enugu. (NHREC/05/01/2008B-FWA00002458-1RB00002323). Approval letters were obtained from HIV center and Obstetrics and Gynaecology Department UNTH Enugu. Written and signed informed consents were obtained from participants. Participants were assured of confidentiality of results.

\section{References}

Aboyeji P, Ijaiya M, Jimoh A, (2004). Knowledge, attitude and practice of cervical smear as a screening procedure for cervical cancer in Ilorin, Nigeria. Trop J Obstet Gynaecol, 21, 114-7.

Adler DH, Kakinami L, Modisenyane T (2012). Increased regression and decreased incidence of HPV-related cervical lesions among HIV-infected women on HAART. AIDS, 26, $1645-52$.

Anorlu R, Igwillo C, Akanmu AA, et al (2011). Prevalence of abnormal cervical smears among patients with HIV in Lagos. Asian Pac J Cancer Prev, 12, 64-7.

Audet CM, Silva MC, Blevins M, et al (2012). Acceptability of cervical cancer screening in rural Mozambique. Health Edu Res, 27, 544-51.

Ayinde OA, Omigbodun AO, Ilesanmi AO, et al (2004). Awareness of cervical cancer, Papanicolaou and its utilization among female undergraduates in Ibadan. Afr $J$ Reprod Health, 8, 68-80.

Blitz S, Baxter J, Raboud J, et al (2013)Evaluation of HIV and highly active antiretroviral therapy on the natural history of human papillomavirus infection and cervical cytopathologic findings in HIV-positive and high-risk HIV-negative women. $J$ Infect Dis, 208, 454-62.

Centers for Disease Control (1993). Revised classification system for HIV infection and expanded surveillance case definition for AIDS among adolescents and adults. MMWR Recommendation Rep, 41, 1-19.

Chama CM, Nggada H, Gashau W, (2005). Cervical dysplasia in HIV infected women in Maiduguri, Nigeria. J Obstet Gynaecol, 25, 286-8.

Chaturvedi A, Madeleine MM, Biggar RJ, Engels EA (2009). Risk of human papillomavirus-associated cancers among persons with AIDS. J Natl Cancer Instit, 101, 1120-30.

Chow EP, Wilson DP, Zhang L (2012). HIV and syphilis co-infection increasing among among men who have sex with men in China: A systematic review and meta-analysis. PLoS One, 6, e22768.

Chukwuali LI, Onuigbo WIB, Mgbor NC (2003). A ten year descriptive analysis of women availing themselves of the cervical cancer screening service at medical women center, Enugu South Eastern Nigeria. Trop J Obstet Gynaecol, 20, 109-12.

Dim CC, Nwagha UI, Ezegwui, HU, Dim NR (2009), The need to incorporate routine cervical cancer counselling and screening in the management of women at the outpatient clinics in Nigeria. J Obstet Gynaecol, 29, 754-6.

Dim CC, Ezegwui HU, Ikeme AC, Nwagha UI, Onyedum CC (2011). Prevalence of cervical squamous intraepithelial lesions among HIV-positive women in Enugu, South-eastern Nigeria. J Obstet Gynaecol, 31, 759-62.

Durowade KA, Osabgemi GK, Salaudeen AG, et al (2012). Prevalence and risk factors of cervical cancer among women in an urban community of Kwara state, north central Nigeria. J Prev Med Hyg, 53, 213-9. 
Ezechi OC, Gab-Okafor CV, Ostergren PO, Odberg PK (2013). Willingness and acceptability of cervical cancer screening among HIV positive Nigerian women. BMC Public Health, 13, 46.

Ezechi OC, Pettersson KO, Okolo CA, Ujah IAO, Ostergren PO (2014). The association between HIV Infection, Antiretroviral Therapy and Cervical Squamous Intraepthelial Lesions in south Western Nigeria Women. PLoS One, 9, e97150.

Federal Ministry of Health (Nigeria), (2006). National survey on HIV/AIDS and reproductive health survey 2005. Federal Ministry of Health, Abuja, Nigeria, accessed $7^{\text {th }}$ June 2016.

Firnhaber C, Westreich D, Schulze D (2012). Highly active antiretroviral therapy and cervical dysplasia in HIV-positive women in South Africa. J Int AIDS Soc, 15, article 17382.

Galadanci HS, Mohammed AZ, Uzoho CC, Jido TA, Ochicha O (2003). Gynaecological malignancies seen in a tertiary health facility in Kano, Northern Nigeria. Tropic J Obstet Gynaecol, 20, 105-8.

Ganesan A, Fieberg A, Agan BK (2012). Results of a 25-year longitudinal analysis of the serologic incidence of syphilis in a cohort of HIV-infected patients with unrestricted access to care. Sexually Transmitted Dis, 39, 440-8.

Gharoro EP, Abedi HO, Okpere EE (1999). Carcinoma of the cervix: Aspects of clinical presentation and management in Benin City. Int J Gynaecol Obstet, 67, 51-3.

Ghebre RG, Grover S, Xu MJ, Chaung LT, Simonds H (2017). Cervical cancer control in HIV-infected women: past, present and future. Gynecol Oncol Rep, 21, 101-8.

Han CP, Lee MY, Tzeng SL, et al (2008). Nuclear Receptor Interaction Protein (NRIP) expression assay using human tissue microarray and immunocytochemistry technology confirming nuclear localization. J Exp Clin Cancer Res, 27, 25.

Hankins C, Coutlee F, Pourreaux K, Lapointe N (2000). The Canadian women's HIV study group. Immunosupression and contraceptive practices associated with persistence of human papillomavirus in HIV-positive and HIV-negative women, presented at XIII ${ }^{\text {th }}$ International AIDS conference, Durban, South Africa, 9-14 July 2000 (Absract MoOrB235).

Huchko MJ, Bukusi EA, Cohen CR (2011). Building capacity for cervical cancer screening in outpatient HIV clinics in the Nyanza province of western Kenya. Int J Gynaecol Obstet, 114, 106-10.

Katz IT, Butler LM, Crankshaw TL, et al (2016). Cervical abnormalities in south African Women Living With HIV With High Screening and Referral Rates. J Glob Oncol, 2, 375-80.

Kim HS, Sardi JE, Katsumata N, et al (2013). Efficacy of neoadjuvant chemotherapy in patients with FIGO stage IB1 to IIA cervical cancer: an international collaborative meta-analysis. Eur J Surg Oncol, 39, 115-24.

Kim SC, Messing S, Shah K, Luque AE (2013). Effect of highly Active Antiretroviral Therapy (HAART) and menopause on risk of progression of cervical dysplasia in Human Immune-Deficiency Virus- (HIV-) Infected Women. Infect Dis Obstet Gynecol, 2013, Article ID 784718, 8 pages, http://dx.doi.org/10.1155/2013/784718. Retrieved on $12^{\text {th }}$ March 2019.

Kyari O, Nggada H, Mairiga A (2004). Malignant tumours of female genital tract in North Eastern Nigeria. East Afr Med J, 22, 57-8.

Lawal I, Agida TE, Offiong, RA, Oluwole PO (2017). Cervical cytology among HIV positive and HIV negative women in a tertiary Hospital in North Central Nigeria: A comparative study. Ann Med Health Sci Res, 7, 308-11.

Menon S, Rossi R, Zdraveska N, Kariisa D (2017). Associations between highly active antiretroviral therapy and the presence of HPV, primalignant and malignant cervical lesions in sub-Saharan Africa, a systematic review: current evidence and direction for future research. BMJ, 7, e015123.

Minkoff H, Zhong Y, Burk RD, et al (2010). Influence of adherent and effective antiretroviral therapy use on human papillomavirus infection and squamous intraepithelial lesions in human immunodeficiency virus-positive women. J Infect Dis, 201, 681-90.

Mohammed A, Avidime S, Oluwole O, Ahmed S (2005). Malignant tumors of the female genital tract in Zaria, Nigeria. An analysis of 513 cases (1993-2003). Tropic $J$ Obstet Gynaecol, 22, 45-6.

Muhammad Z, Usman IH, Datti ZA, et al (2017). Incidence and risk factors of cervical dysplasia among HIV positive and Negative women in AKTH, Nigeria. Sahel Med J, 20, 160-7.

Mutihir J (2005). Common gynecological conditions at the Jos University Teaching Hospital, North central, Nigeria. Trop J Obstet Gynaecol, 22, 57-8.

Mutyaba T, Mmiro FA, Weiderpass E (2006). Knowledge, attitudes and practice on cervical cancer screening among the medical workers of Mutago hospital Uganda. BMC Med $E d u, \mathbf{6}, 13$.

Oakeshott P, Aghaizu A, Reid F, et al (2012). Frequency and risk factors for prevalent, incident, and persistent genital carcinogenic human papillomavirus infection in sexually active women: Community based cohort study. BMJ, 344, e4168.

Odafe S, Torpey K, Khamofu H, et al (2013 ). Integrating cervical cancer screening with HIV care in a district hospital in Abuja, Nigeria. Nigeria Med J, 54, 176-84.

Ononogbu U, Almujutaba M, Modibbo F, et al., (2013). Cervical cancer risk factor among HIV-infected Nigerian women. BMC Public Health, 13, 582.

Partridge JM, Hughes JP, Feng Q, et al (2007). Genital human papillomavirus infection in men: Incidence and risk factors in a cohort of university students. J Infect Dis, 196, 1128-36.

Pimentel VM, Jiang X, Mandavilli S, Umenyi NC, Schnaz PF (2013). Prevalence o high-risk cervical human papillomavirus and squamous intraepithelial lesion in Nigeria. J Low Genit Tract Dis, 17, 203-9

Pocock SJ (1983). Clinical Trials: A practical Approach, Wiley Sealed Envelope Ltd. (2012). Power calculator for binary outcome superiority trial. [online] available from http:// www.sealedenvelope.com/power/binary-superiority/ (accessed Wed, 24 Aug 2016 and Wed, 22 Feb, 2017).

Solomon D, Davey D, Kurman R, et al (2002). The Bethesda system terminology for reporting results of cervical cytology. JAMA, 287, 2114-8.

Torre LA, Bra F, Siegel RL, et al (2012). Global cancer statistics. CA Cancer J Clin, 65, 87-108.

Ugboaja JO, Oguejiofor CO, Obi BN (2017). Sociodemographic determinants of abnormal cervical cytology among HIV positive women in Nnewi, Nigeria. Int J Med Med Sci, 9, $119-25$.

UNAIDS (2014). 3.4 million Nigerians contracted HIV/ AIDS in 2014. Available at http://www.informationng. com/2015/09/3-4m-nigerianscontracte-hivaids-in-2014-u Retreived on $15^{\text {th }}$ April, 2019.

WHO (2012). Media centre, cancer facts sheets, February 2012, http://www.who.int/medicalcentre/factsheets/fs297/en/ viewed 10th June2016.

World Health Organization (2004). Scaling up antiretroviral therapy in resource-limited settings: treatment guidelines for a public health approach. IAPAC.

World Health Organization (2014). Reproductive Health, World Health Organization. Comprehensive Cervical Cancer 


\section{Cornelius Osinachi Ogu et al}

Control: A Guide to Essential Practice. $2^{\text {nd }}$ ed. World Health Organization;. Chronic diseases, health promotion.

WHO/ICO. 2010. Information Centre on HPV and Cervical Cancer. Human papillomavirus and related cancers in Nigeria: Summary report 2010. Available at: http://apps. who.int/hpvcentre/statistics/dynamic/ico/country_pdf/NGA. pdf Accessed 12 July 2018.

\section{@ $(0 \otimes$}

This work is licensed under a Creative Commons AttributionNon Commercial 4.0 International License. 